Article

\title{
Thermoeconomic Analysis and Optimization of a New Combined Supercritical Carbon Dioxide Recompression Brayton/Kalina Cycle
}

\author{
S. Mohammad S. Mahmoudi ${ }^{1, *}$, Ata D. Akbari ${ }^{1}$ and Marc A. Rosen ${ }^{2}$
}

1 Faculty of Mechanical Engineering, University of Tabriz, Tabriz 51666-16471, Iran; ad_akbari@tabrizu.ac.ir

2 Faculty of Engineering and Applied Science, University of Ontario Institute of Technology, Oshawa, ON L1H 7K4, Canada; marc.rosen@uoit.ca

* Correspondence: s_mahmoudi@tabrizu.ac.ir; Tel.: +98-411-339-2487

Academic Editor: Barry D. Solomon

Received: 4 September 2016; Accepted: 17 October 2016; Published: 24 October 2016

\begin{abstract}
A new combined supercritical $\mathrm{CO}_{2}$ recompression Brayton/Kalina cycle (SCRB/KC) is proposed. In the proposed system, waste heat from a supercritical $\mathrm{CO}_{2}$ recompression Brayton cycle (SCRBC) is recovered by a Kalina cycle (KC) to generate additional electrical power. The performances of the two cycles are simulated and compared using mass, energy and exergy balances of the overall systems and their components. Using the SPECO (Specific Exergy Costing) approach and employing selected cost balance equations for the components of each system, the total product unit costs of the cycles are obtained. Parametric studies are performed to investigate the effects on the SCRB/KC and SCRBC thermodynamic and thermoeconomic performances of key decision parameters. In addition, considering the exergy efficiency and total product unit cost as criteria, optimization is performed for the SCRBC and SCRB/KC using Engineering Equation Solver software. The results indicate that the maximum exergy efficiency of the SCRB/KC is higher than that of the SCRBC by up to $10 \%$, and that the minimum total product unit cost of the SCRB/KC is lower than that of the SCRBC by up to $4.9 \%$.
\end{abstract}

Keywords: recompression supercritical carbon dioxide cycle; Kalina cycle; exergy analysis; thermoeconomics; optimization

\section{Introduction}

Global warming, environmental pollution and growing demand for energy have increased attention on the efficient use of energy resources. In this regard, waste heat recovery from industry can play an important role as it enhances thermodynamic efficiency of energy conversion systems [1]. However, the thermodynamic efficiency of an energy conversion system affects the product unit cost, which is a key parameter in assessing the system performance economically. The product unit cost can be determined by thermoeconomics, which combines the principles of thermodynamics and economics. This parameter is a major criterion in evaluating the economic effectiveness of waste heat utilization.

Among the configurations proposed for some plants, such as future nuclear power plants and concentrated solar power (CSP) plants and refrigeration systems, the supercritical $\mathrm{CO}_{2}\left(\mathrm{~S}-\mathrm{CO}_{2}\right)$ cycle is considered promising as it is simple, compact, secure and economic [2]. The cycle working fluid, carbon dioxide, is a non-toxic and non-combustible material [3]. Another advantage of $\mathrm{CO}_{2}$ is the sudden change of its thermophysical properties at its near critical point. This characteristic brings about a lower value of compression work so that the efficiency of the $\mathrm{S}-\mathrm{CO}_{2}$ cycle is high [2]. The cycle was first proposed by Feher and Angelino in 1968 [4,5]. Dostal in 2004 compared the performances of a S- $\mathrm{CO}_{2}$ Brayton cycle and a Rankine cycle of similar generation capacity and reported a significantly reduced size of turbomachinery and higher efficiencies for the $\mathrm{S}-\mathrm{CO}_{2}$ cycle [6]. Having used a low-grade heat 
source, Cayer et al. performed a detailed analysis for a carbon dioxide transcritical power cycle [7]. They reported the work in four steps: energy analysis, exergy analysis, finite size thermodynamics and heat exchanger surface calculation. They concluded that there exists an optimum high pressure for each of the mentioned steps. Angelino and Invernizzi used low-temperature liquefied natural gas (LNG) as a heat sink in proposing new configurations for the $\mathrm{CO}_{2}$ power cycle in order to improve the system performance [8]. Sarkar performed an exergy analysis for the SCRBC and optimized its performance [9]. He reported that the irreversibilities in heat exchangers are higher than those in turbo-machinery and that the high temperature regenerator (HTR) is more effective than the low temperature regenerator (LTR) at raising the cycle efficiency. In another paper, Sarkar and Bhattacharyya examined the effect of reheating on SCRBC performance and studied the optimized condition of the cycle when the operating parameters and component performance are changed [10]. Wang et al. assessed the effects on the optimized condition of the $\mathrm{S}-\mathrm{CO}_{2}$ cycle of varying thermodynamic parameters. They used a genetic algorithm and an artificial neural network for the optimization [11]. Yari and Sirusazar combined the SCRBC with a transcritical $\mathrm{CO}_{2}$ cycle for performance enhancement [12]. Jeong et al. optimized the performance of a S- $\mathrm{CO}_{2}$-based binary gas mixture Brayton cycle with a sodium-cooled fast reactor. They selected a mixture of $\mathrm{CO}_{2}$ and some other gases as the working fluid so that the critical point of the working fluid is shifted [13]. Yoon et al. concluded that cycle simplicity, high efficiency and compact turbomachinery and heat exchangers are significant advantages for the $\mathrm{S}-\mathrm{CO}_{2}$ cycle [14]. They stated that the $\mathrm{S}-\mathrm{CO}_{2}$ cycle is appropriate for small and medium size water-cooled nuclear reactors. Thermodynamic analyses were performed by Kim et al. for a transcritical $\mathrm{CO}_{2}$ cycle utilizing both low and high temperature heat sources [15]. Floyd et al. described the off-design response of a SCRBC coupled with a sodium fast reactor as the heat sink temperature changes [16]. Singh et al. proposed an extremum-seeking controller to enhance the performance of a direct heated $\mathrm{S}-\mathrm{CO}_{2}$ closed loop Brayton cycle for a fluctuating solar input energy and ambient temperature [17]. Moullec showed that an efficiency of $50 \%$ can be achieved for a coal power plant with a S-CO $\mathrm{CO}_{2}$ Brayton cycle when the maximum cycle temperature and pressure are $893 \mathrm{~K}$ and 300 bar, respectively [18]. Nithyanandam and Pitchumani investigated the thermodynamic and economic performances of a concentrating solar power (CSP) power-tower system utilizing Rankine and $\mathrm{S}-\mathrm{CO}_{2}$ cycles integrated with encapsulated phase change material for thermal energy storage or thermal energy storage with embedded heat pipes [19].

Dai et al. compared the performance of a transcritical Rankine cycle for various working fluids, including zeotropic mixtures of $\mathrm{CO}_{2}$ and traditional working fluids, and pure $\mathrm{CO}_{2}$ [20]. They reported that, when zeotropic mixtures are used, the pressure level in the cycle is reduced and the thermal efficiency is improved. Akbari and Mahmoudi optimized the thermodynamic and thermoeconomic performance of a combined cycle consisting of a SCRBC and an Organic Rankine cycle (ORC) [2]. Using the turbine bleed gas for regenerative heating, Mondal and De showed that a transcritical $\mathrm{CO}_{2}$ power cycle results in higher 1st and 2nd law efficiencies [21]. Hu et al. compared the performance of a supercritical gas Brayton cycle for several types of working fluids such as $\mathrm{CO}_{2}$-based binary mixtures and pure carbon dioxide. They found higher efficiencies for both $\mathrm{CO}_{2}-\mathrm{He}$ and $\mathrm{CO}_{2}-\mathrm{Kr}$ mixtures [22]. Energy and exergy analyses were carried out for four different $\mathrm{S}-\mathrm{CO}_{2}$ Brayton cycle configurations integrated with solar central receivers by Padilla et al. [23]. They reported that the recompression cycle with primary compression intercooling attained the highest thermal efficiency. Gholamian et al. proposed and analyzed a new cogeneration system combining a biomass fuelled gas turbine and a S-CO $\mathrm{CO}_{2}$ cycle coupled with a domestic water heater. They showed that the exergy efficiency and $\mathrm{CO}_{2}$ emissions are higher for the cogeneration system, compared to the stand alone gas turbine and power generation systems [24].

The above survey shows that recovering waste heat from a SCRBC system by a bottoming cycle, such as an ORC, improves the energy conversion efficiency of the system. In addition, Kalina cycles can compete with the ORC in utilizing low temperature heat sources to produce electricity. They perform better than the ORC in some respects, e.g., its boiling/condensing process occurs at a variable 
temperature so that the exergy destruction in the evaporator and condenser is reduced [25]. To our knowledge, the Kalina cycle (KC) has not been used to recover the waste heat from the SCRBC for producing additional electricity and no information in this regard has been reported. The present work fulfills this lack of information by proposing and analyzing a new combined supercritical $\mathrm{CO}_{2}$ recompression Brayton/Kalina cycle (SCRB/KC) in which waste heat from the pre-cooler of the SCRBC is utilized to drive a KC. The investigation is performed from the viewpoints of both thermodynamics and thermoeconomics. Through a parametric study, the influence of some important decision parameters on the second law efficiency and the product unit cost of the SCRBC and SCRB/KC are studied. Finally, the thermodynamic and thermoeconomic performances of the SCRBC and the $\mathrm{SCRB} / \mathrm{KC}$ are optimized. The objective is to improve understanding of the new system and we expect that the obtained results will be useful in designing a more efficient heat recovery system for nuclear power plants.

\section{System Description and Assumptions}

Figure 1 shows a schematic diagram of the proposed cycle in which the SCRBC is combined with the $\mathrm{KC}$ so that heat discarded from pre-cooler1 and the superheater of the SCRBC is used to drive the $\mathrm{KC}$. The reactor exit stream enters turbine1 where it expands, producing power. The expanded stream then rejects heat in the HTR and LTR before being split into two parts. One part flows to compressor2 and the other to the superheater and pre-cooler1, where it rejects heat to drive the $\mathrm{KC}$. The $\mathrm{CO}_{2}$ exiting pre-cooler1 rejects additional heat in pre-cooler2 before being compressed in compressor1. The compressed $\mathrm{CO}_{2}$ leaving compressor 1 is heated in the LTR before mixing with the $\mathrm{CO}_{2}$ stream exiting compressor2. The mixture (stream 10) flows to the HTR where it is heated before entering the reactor.

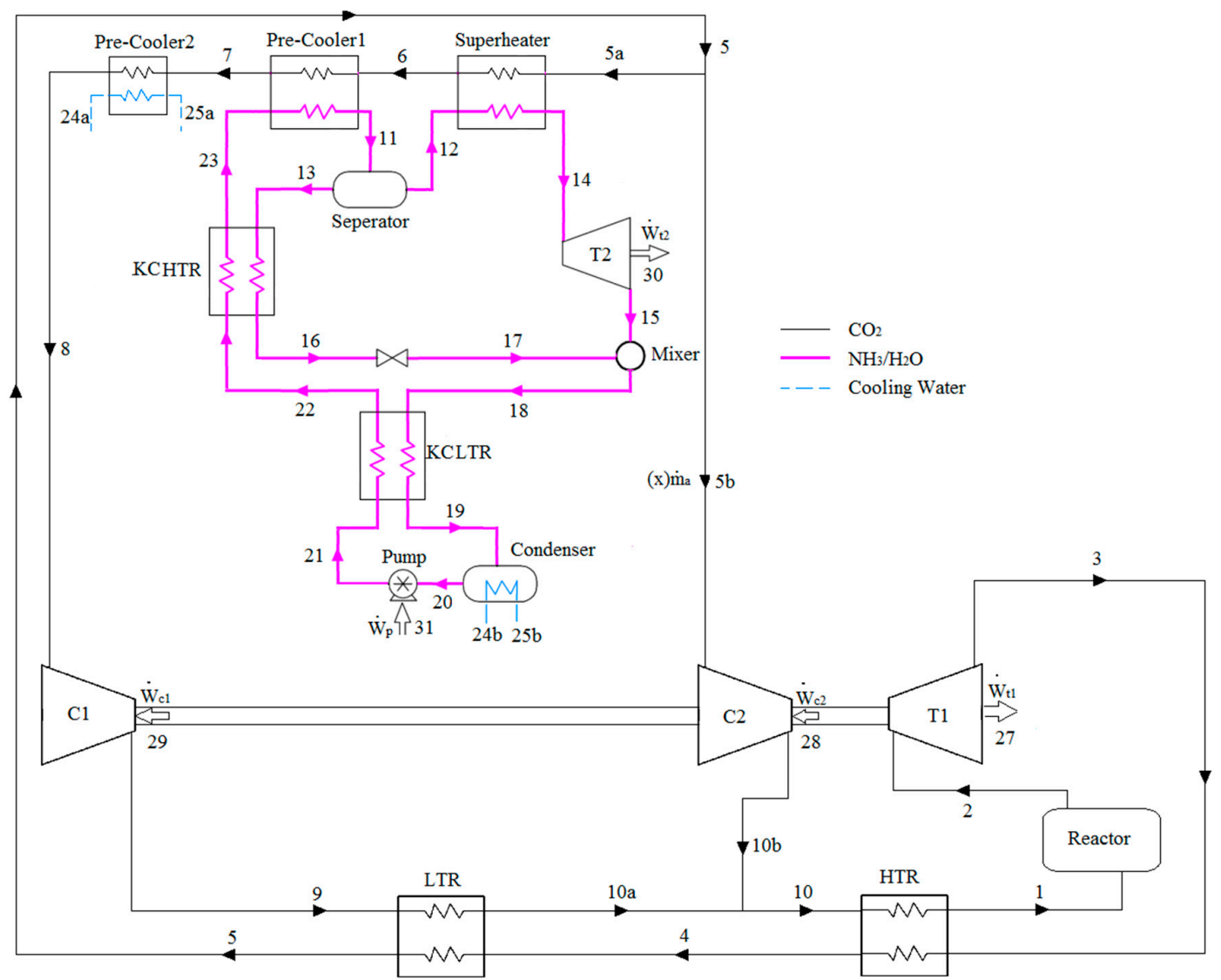

Figure 1. Schematic diagram for the proposed supercritical $\mathrm{CO}_{2}$ recompression Brayton/Kalina cycle (SCRB/KC). 
In the $\mathrm{KC}$, the saturated ammonia-water liquid exits the condenser and is pumped to the Kalina cycle low temperature recuperator (KCLTR) and the Kalina cycle high temperature recuperator (KCHTR) where heat recovery takes place. The stream exiting the KCLTR flows to pre-cooler1, where it is heated by the $\mathrm{CO}_{2}$ before passing to the separator. In the separator the working fluid is separated into a rich ammonia-water mixture saturated vapor (stream 12) and a poor ammonia-water mixture saturated liquid (stream 13). The saturated vapor is then superheated in the superheater by the $\mathrm{CO}_{2}$ before entering turbine2. The saturated ammonia-water liquid mixture flows to the KCHTR where it is cooled before passing to the expansion valve. The stream exiting the expansion valve flows to the mixer and mixes with the stream exiting turbine2. The mixture then passes to the KCLTR, where it rejects heat, before flowing to the condenser, completing the Kalina cycle.

The following assumptions are used:

- The system operation is at steady state.

- Pressure drops in all components and connecting lines, except turbines, compressors and the pump, are negligible [2].

- The turbines, the pump and the compressors are taken to have specific isentropic efficiencies.

- No changes occur in kinetic and potential energies.

- The cooling water entering the pre-cooler and the condenser is at environmental conditions.

- The LTR and HTR have specific effectiveness values.

- The state of the ammonia-water solution is saturated at both the condenser and separator exits.

\section{Thermodynamic Analysis}

Considering each system component as a control volume, the principles of conservation of mass and conservation of energy as well as exergy balances are applied. The solution to the obtained equations and the equations associated with thermodynamic properties simulate the cycle performance. Thermoeconomic analyses are carried out using the exergy values obtained from the simulation. Neglecting electrical, magnetic, nuclear and surface tension effects and the changes in kinetic and potential exergies, the total exergy rate of a stream is the sum of its physical and chemical exergy rates [26]:

$$
\dot{E}=\dot{E}_{p h}+\dot{E}_{c h}
$$

The physical exergy rate is given by:

$$
\dot{E}_{p h}=\dot{m}\left[\left(h-h_{0}\right)-T_{0}\left(s-s_{0}\right)\right]
$$

To calculate the chemical exergy rate of an ammonia-water mixture, the following expression in terms of standard chemical exergies of ammonia and water $\left(e_{c h, \mathrm{NH}_{3}}^{0}\right.$ and $\left.e_{c h, \mathrm{H}_{2} \mathrm{O}}^{0}\right)$ is used [27]:

$$
\dot{E}_{c h}=\dot{m}\left[\left(\frac{X}{M_{\mathrm{NH}_{3}}}\right) e_{c h, \mathrm{NH}_{3}}^{0}+\left(\frac{X}{M_{\mathrm{H}_{2} \mathrm{O}}}\right) e_{c h, \mathrm{H}_{2} \mathrm{O}}^{0}+\bar{R} T_{0} X_{i} \ln X_{i}\right]
$$

The third term in Equation (3) is neglected in the analysis. For the $\mathrm{CO}_{2}$, however, the chemical exergy does not change from one point to another and, therefore, it is not taken into account.

The effectivenesses for heat exchangers in the SCRBC are as follows:

$$
\begin{gathered}
\epsilon_{H T R}=\frac{\mathrm{T}_{3}-\mathrm{T}_{4}}{\mathrm{~T}_{3}-\mathrm{T}_{10}} \\
\epsilon_{\text {LTR }}=\frac{\mathrm{T}_{4}-\mathrm{T}_{5}}{\mathrm{~T}_{4}-\mathrm{T}_{9}}
\end{gathered}
$$


The 1st law efficiency for the SCRBC/KC is expressed as

$$
\eta_{t h}=\frac{\dot{\mathrm{W}}_{\mathrm{net}, \mathrm{CO}_{2}}+\dot{\mathrm{W}}_{\mathrm{net}, \mathrm{KC}}}{\dot{\mathrm{Q}}_{\mathrm{R}}}
$$

In Equation (6), $\dot{\mathrm{W}}_{\text {net, }, \mathrm{CO}_{2}}$ and $\dot{\mathrm{W}}_{\text {net,KC }}$ denote the net generated power in the SCRBC and KC, respectively, and $\dot{Q}_{\mathrm{R}}$ denotes the heat transferred to the reactor.

The exergy efficiency for the proposed cycle is expressed as:

$$
\eta_{e x}=\frac{\dot{\mathrm{W}}_{\mathrm{net}, \mathrm{CO}_{2}}+\dot{\mathrm{W}}_{\mathrm{net}, \mathrm{KC}}}{\dot{\mathrm{E}}_{\mathrm{R}}}
$$

where the denominator $\dot{E}_{R}$ is the exergy input to the reactor:

$$
\dot{\mathrm{E}}_{\mathrm{R}}=\dot{\mathrm{Q}}_{\mathrm{R}}\left(1-\frac{\mathrm{T}_{0}}{\mathrm{~T}_{\mathrm{R}}}\right)
$$

Data from the literature are used to verify the models developed for the SCRBC [2] and the $\mathrm{KC}$ [28]. For the case of the SCRBC, a validation has been previously reported by the authors [2]. For the KC case, a validation is shown in Table 1, which compares the results obtained from the present work and those reported in the literature for the KC [28]. Good agreement between the two is observed

\begin{tabular}{|c|c|c|c|c|c|c|c|c|}
\hline \multirow{2}{*}{ Stream } & \multicolumn{2}{|c|}{ Temperature (K) } & \multicolumn{2}{|c|}{ Pressure (Bar) } & \multicolumn{2}{|c|}{ Ammonia Concentration } & \multicolumn{2}{|c|}{ Mass Flow Rate } \\
\hline & Present & Ref. [28] & Present & Ref. [28] & Present & Ref. [28] & Present & Ref. [28] \\
\hline 11 & 389.15 & 389.15 & 32.3 & 32.3 & 0.82 & 0.82 & 16.8 & 16.8 \\
\hline 12 & 389.15 & 389.15 & 32.3 & 32.3 & 0.9718 & 0.97 & 11.27 & 11.4 \\
\hline 13 & 389.15 & 389.15 & 32.3 & 32.3 & 0.5104 & 0.5 & 5.527 & 5.4 \\
\hline 14 & 389.15 & - & 32.3 & - & 0.5104 & - & 5.527 & - \\
\hline 15 & 314.45 & 316.15 & 6.6 & 6.6 & 0.9718 & 0.97 & 11.27 & 11.4 \\
\hline 16 & 318.44 & 319.15 & 31.3 & 31.3 & 0.5104 & 0.5 & 5.527 & 5.4 \\
\hline 17 & 318.85 & - & 6.6 & - & 0.5104 & - & 5.527 & - \\
\hline 18 & 318.44 & 319.15 & 6.6 & 6.6 & 0.82 & 0.82 & 16.8 & 16.8 \\
\hline 19 & 303.05 & 303.15 & 5.6 & 5.6 & 0.82 & 0.82 & 16.8 & 16.8 \\
\hline 20 & 281.15 & 281.15 & 4.769 & 4.6 & 0.82 & 0.82 & 16.8 & 16.8 \\
\hline 21 & 281.59 & 281.15 & 35.3 & 35.3 & 0.82 & 0.82 & 16.8 & 16.8 \\
\hline 22 & 313.44 & 314.15 & 34.3 & 34.3 & 0.82 & 0.82 & 16.8 & 16.8 \\
\hline 23 & 336.02 & 336.15 & 33.3 & 33.3 & 0.82 & 0.82 & 16.8 & 16.8 \\
\hline & Present work & Ref. [28] & & & & & & \\
\hline Net power $(\mathrm{kW})$ & 2201 & 2194.8 & & & & & & \\
\hline
\end{tabular}
in Table 1.

Table 1. Comparison between present results and those of Reference [28] for the Kalina cycle. ${ }^{a}$

\section{Thermoeconomic Analysis}

The concepts of thermodynamics and economics are combined in thermoeconomics. It provides information about the cost effectiveness of energy conversion systems based on the results obtained from exergy analysis. One of the main objectives in thermoeconomics is the determination of the unit product cost, the value of which must be minimized. In order to calculate this parameter, the cost balance equation is applied to each system component. The cost rate balance equation for a system component receiving thermal energy and producing electricity is expressed as [26]:

$$
\sum \dot{C}_{o u t, k}+\dot{C}_{w, k}=\sum \dot{C}_{i n, k}+\dot{C}_{q, k}+\dot{Z}_{k}
$$

where

$$
\dot{C}=c \dot{E}
$$


and $c$ is the specific exergy stream cost. Equation (9) balances the cost rates associated with the exergy streams entering and exiting the component and the investment cost rate related to the component. The investment cost rate, $\dot{Z}_{k}$, for the $k$ th component is the sum of the total capital investment rate, $\dot{Z}_{k}{ }^{C I}$, and the operation and maintenance cost rate, $\dot{Z}_{k}{ }^{O M}$ :

$$
\dot{Z}_{k}=\dot{Z}_{k}^{C I}+\dot{Z}_{k}^{O M}
$$

For the $k$ th component, the annual levelized capital investment rate is obtained as follows [26]:

$$
\dot{Z}_{k}^{C I}=\left(\frac{C R F}{\tau}\right) Z_{k}
$$

where $C R F$ and $\tau$ denote the capital recovery factor and the annual plant operation hours, respectively. The CRF is expressed as follows [26]:

$$
C R F=\frac{i_{r}\left(1+i_{r}\right)^{n}}{\left(1+i_{r}\right)^{n}-1}
$$

where $i_{r}$ is the interest rate and $n$ is the economic life of the system in years. Appendix A provides the cost functions for each system component.

The annual levelized operating and maintenance cost rate for component $k$ can be expressed as [26]:

$$
\dot{Z}_{k}^{O M}=\gamma_{k} \dot{Z}_{k}+\omega_{k} \dot{E}_{p, k}+\dot{R}_{k}
$$

where $\gamma_{k}$ and $\omega_{k}$ are the coefficients for the fixed and variable operating and maintance cost rates related to the $k$ th component, respectively, and $\dot{R}_{k}$ accounts all the other operating and maintenance cost rates which do not depend on the investment cost and product exergy. The two last terms in Equation (14) are neglected in the present work because of their much lower values than the first term [29].

Interest rate, annual plant operation hours, coefficient for the operating and maintenance cost $\gamma_{k}$ and number of years of economic life time values are given in Table 2.

Table 2. Economic data used in the simulation [2].

\begin{tabular}{cc}
\hline Parameter & Value \\
\hline$i_{r}(\%)$ & 12 \\
$n($ year $)$ & 20 \\
$\tau(\mathrm{h})$ & 8000 \\
$\gamma_{k}$ & 0.06 \\
\hline
\end{tabular}

The Specific Exergy Costing (SPECO) method is used in this work [30]. There are three main steps in this method: (1) identifying exergy streams; (2) defining the fuel and product for each system component; and (3) applying cost-balance equations [30].

The fuel represents the input exergy to generate the product and is not necessarily an actual fuel. The fuel for a component can be the product of the previous component. In Table 3, the fuel and product exergy definitions are given for each system component in the SCRB/KC. In the KC, there is no product for the throttling valve. This component, however, serves the mixer. Therefore, the throttling valve and mixer are treated as a single unit [29] for which the product is defined as indicated in Table 3.

The cost balances along with the auxiliary costing equations for each system component are listed in Table 4. The solution to these equations gives the costs associated with each material and energy stream in the proposed system, i.e., $\left\{\dot{C}_{1}, \dot{C}_{2}, \ldots \dot{C}_{30}\right\}$. The unit costs of all exergy streams can be calculated using Equation (10). 
Table 3. Fuel-product definitions for the SCRB/KC components.

\begin{tabular}{ccc}
\hline Component & Fuel Exergy & Product Exergy \\
\hline Compressor1 & $\dot{E}_{29}\left(\dot{W}_{C 1}\right)$ & $\dot{E}_{9}-\dot{E}_{8}$ \\
LTR & $\dot{E}_{4}-\dot{E}_{5}$ & $\dot{E}_{10 a}-\dot{E}_{9}$ \\
HTR & $\dot{E}_{3}-\dot{E}_{4}$ & $\dot{E}_{1}-\dot{E}_{10}$ \\
Reactor & $\dot{E}_{1}-\dot{E}_{c o r e}$ & $\dot{E}_{2}$ \\
Turbine1 & $\dot{E}_{2}-\dot{E}_{3}$ & $\dot{E}_{27}\left(\dot{W}_{T 1}\right)$ \\
Compressor2 & $\dot{E}_{28}\left(\dot{W}_{C 2}\right)$ & $\dot{E}_{10 b}-\dot{E}_{5 b}$ \\
Superheater & $\dot{E}_{5 a}-\dot{E}_{6}$ & $\dot{E}_{14}-\dot{E}_{12}$ \\
Pre-cooler1 & $\dot{E}_{6}-\dot{E}_{7}$ & $\dot{E}_{11}-\dot{E}_{23}$ \\
Pre-cooler2 & $\dot{E}_{7}-\dot{E}_{8}$ & $\dot{E}_{25 a}-\dot{E}_{24 a}$ \\
Separator & $\dot{E}_{11}$ & $\dot{E}_{12}+\dot{E}_{13}$ \\
Turbine2 & $\dot{E}_{14}-\dot{E}_{15}$ & $\dot{E}_{30}\left(\dot{W}_{T 2}\right)$ \\
Mixer and throttling valve & $\dot{E}_{16}+\dot{E}_{18}$ & $\dot{E}_{20}$ \\
KCLTR & $\dot{E}_{18}-\dot{E}_{19}$ & $\dot{E}_{22}-\dot{E}_{21}$ \\
Condenser & $\dot{E}_{19}-\dot{E}_{20}$ & $\dot{E}_{25 b}-\dot{E}_{24 b}$ \\
Pump & $\dot{E}_{31}\left(\dot{W}_{p}\right)$ & $\dot{E}_{21}-\dot{E}_{20}$ \\
KCHTR & $\dot{E}_{13}-\dot{E}_{16}$ & $\dot{E}_{23}-\dot{E}_{22}$ \\
\hline
\end{tabular}

The terms in parenthesis indicate power corresponding to the exergy rate shown by the previous term.

Table 4. Cost balance and auxiliary equations for the SCRB/KC components.

\begin{tabular}{|c|c|c|}
\hline Component & Cost Balance & Auxiliary Equations \\
\hline Compressor1 & $\dot{C}_{9}=\dot{C}_{29}+\dot{C}_{8}+\dot{Z}_{C 1}$ & \\
\hline LTR & $\dot{C}_{5}+\dot{C}_{10 a}=\dot{C}_{9}+\dot{C}_{4}+\dot{Z}_{L T R}$ & $\frac{\dot{C}_{4}}{\dot{E}_{4}}=\frac{\dot{C}_{5}}{\dot{E}_{5}}$ or $c_{4}=c_{5}$ \\
\hline HTR & $\dot{C}_{1}+\dot{C}_{4}=\dot{C}_{10}+\dot{C}_{3}+\dot{Z}_{H T R}$ & $\frac{\dot{C}_{3}}{\dot{E}_{3}}=\frac{\dot{C}_{4}}{\dot{E}_{4}}$ or $c_{3}=c_{4}$ \\
\hline Reactor & $\dot{C}_{2}=\dot{C}_{f u e l}+\dot{C}_{1}+\dot{Z}_{R}$ & \\
\hline Turbine1 & $\dot{C}_{3}+\dot{C}_{27}=\dot{C}_{2}+\dot{Z}_{T 1}$ & $\frac{\dot{C}_{3}}{\dot{E}_{3}}=\frac{\dot{C}_{2}}{\dot{E}_{2}}$ or $c_{2}=c_{3}$ \\
\hline Compressor2 & $\dot{C}_{9 b}=\dot{C}_{28}+\dot{C}_{5 b}+\dot{Z}_{C 2}$ & $\begin{array}{l}\frac{\dot{C}_{28}}{\dot{E}_{28}}=\frac{\dot{C}_{29}}{\dot{E}_{29}} \text { or } c_{28}=c_{29} \\
\frac{\dot{C}_{28}}{\dot{E}_{28}}=\frac{\dot{C}_{27}}{\dot{E}_{27}} \text { or } c_{28}=c_{27}\end{array}$ \\
\hline Superheater & $\dot{C}_{6}+\dot{C}_{14}=\dot{C}_{12}+\dot{C}_{5 a}+\dot{Z}_{s h}$ & $\frac{\dot{C}_{6}}{\dot{E}_{6}}=\frac{\dot{C}_{5 a}}{\dot{E}_{5 a}}$ or $c_{6}=c_{5 a}$ \\
\hline Pre-cooler1 & $\dot{C}_{7}+\dot{C}_{11}=\dot{C}_{23}+\dot{C}_{6}+\dot{Z}_{p c 1}$ & $\frac{\dot{C}_{6}}{\dot{E}_{6}}=\frac{\dot{C}_{7}}{\dot{E}_{7}}$ or $c_{6}=c_{7}$ \\
\hline Pre-cooler2 & $\dot{C}_{25 a}+\dot{C}_{8}=\dot{C}_{24 a}+\dot{C}_{7}+\dot{Z}_{p c 2}$ & $\dot{C}_{24 a}=0$ \\
\hline Separator & $\dot{C}_{12}+\dot{C}_{13}=\dot{C}_{11}+\dot{Z}_{s p}$ & $\frac{\dot{C}_{12}}{\dot{E}_{12}}=\frac{\dot{C}_{13}}{\dot{E}_{13}}$ or $c_{12}=c_{13}$ \\
\hline Turbine2 & $\dot{C}_{30}+\dot{C}_{15}=\dot{C}_{14}+\dot{Z}_{T 2}$ & $\frac{\dot{C}_{14}}{\dot{E}_{14}}=\frac{\dot{C}_{15}}{\dot{E}_{15}}$ or $c_{14}=c_{15}$ \\
\hline Mixer and throttling valve & $\dot{C}_{18}=\dot{C}_{15}+\dot{C}_{16}+\dot{Z}_{\text {valve }}+\dot{Z}_{\text {mix }}$ & \\
\hline KCLTR & $\dot{C}_{22}+\dot{C}_{19}=\dot{C}_{18}+\dot{C}_{21}+\dot{Z}_{L T R K C}$ & $\frac{\dot{C}_{18}}{\dot{E}_{18}}=\frac{\dot{C}_{19}}{\dot{E}_{19}}$ or $c_{18}=c_{19}$ \\
\hline Condenser & $\dot{C}_{25 a}+\dot{C}_{20}=\dot{C}_{24 a}+\dot{C}_{19}+\dot{Z}_{c o n d}$ & $\dot{C}_{24 b}=0$ \\
\hline Pump & $\dot{C}_{21}=\dot{C}_{20}+\dot{C}_{31}+\dot{Z}_{p}$ & $\frac{\dot{C}_{30}}{\dot{E}_{30}}=\frac{\dot{C}_{32}}{\dot{E}_{32}}$ or $c_{30}=c_{32}$ \\
\hline KCHTR & $\dot{C}_{23}+\dot{C}_{16}=\dot{C}_{13}+\dot{C}_{22}+\dot{Z}_{\text {HTRKC }}$ & $\frac{\dot{C}_{13}}{\dot{E}_{13}}=\frac{\dot{C}_{16}}{\dot{E}_{16}}$ or $c_{13}=c_{16}$ \\
\hline
\end{tabular}


The total product unit cost, which is the main criteria in optimizing the economic performance of the system, is calculated as follows [2]:

$$
c_{\mathrm{p}, \text { tot }}=\frac{\sum_{i=1}^{n_{k}} \dot{Z}_{k}+\dot{C}_{f u e l}}{\sum_{i=1}^{n_{p}} \dot{E}_{p_{i}}}
$$

For each component of the SCRBC and the SCRB/KC, important thermoeconomic variables are calculated, such as exergy destruction rate $\dot{E}_{D}$; exergy destruction cost rate $\dot{C}_{D}$; investment cost rate $\dot{Z}$; relative cost difference $r$; and exergoeconomic factor $f$. The exergy destruction cost rate for the $k$ th component is defined as [26]:

$$
\dot{C}_{D, k}=c_{F, k} \dot{E}_{D, k}
$$

where $c_{F, k}$ is the average unit cost of the fuel provided to the component. The definitions for $f$ and $r$ for the $k$ th component are as follows [26]:

$$
\begin{gathered}
f_{k}=\frac{\dot{Z}_{K}}{\dot{Z}_{K}+c_{F, k}\left(\dot{E}_{D, K}+\dot{E}_{L, K}\right)} \\
r_{k}=\frac{c_{P, k}-c_{F, k}}{c_{F, k}}
\end{gathered}
$$

where $\dot{E}_{L, K}$ and $c_{P, k}$ are the exergy loss rate and product unit cost for the $k$ th component, respectively. Taking the input exergy for the reactor core as the input exergy from nuclear fission $\left(\dot{E}_{c o r e}\right)$, the exergy balance for the reactor core is expressed as follows [29]:

$$
\dot{E}_{1}+\dot{E}_{\text {core }}=\dot{E}_{2}+\dot{E}_{D, R}
$$

According to the thermoeconomic evaluation guidelines presented by Bejan et al. [26], in designing a new system, the first design changes initially must be applied to the component for which the sum of $\dot{C}_{D}+\dot{Z}+\dot{C}_{\mathrm{L}}$ is the highest.

\section{Results and Discussion}

The input data utilized for the simulation are shown in Table 5.

Table 5. Input data for the simulation.

\begin{tabular}{cc}
\hline Parameter & Value \\
\hline $\mathrm{T}_{\mathrm{O}}(\mathrm{K})$ & 298.15 \\
$\mathrm{P}_{\mathrm{O}}(\mathrm{bar})$ & 1.01 \\
$\mathrm{P}_{1}($ bar $)$ & $74^{\mathrm{a}}$ \\
$\mathrm{PR}_{\mathrm{C}}$ & $2.2-4.2$ \\
$\mathrm{~T}_{\max }(\mathrm{K})$ & $823.15^{\mathrm{a}}$ \\
$\mathrm{T}_{7}(\mathrm{~K})$ & $308.15^{\mathrm{a}}$ \\
$\mathrm{T}_{\mathrm{r}}(\mathrm{K})$ & $1073.15^{\mathrm{a}}$ \\
$\eta_{t 1}(\%)$ & $0.9^{\mathrm{a}}$ \\
$\eta_{c}(\%)$ & $0.85^{\mathrm{a}}$ \\
$\epsilon_{L T R}$ and $\epsilon_{H T R}$ & $0.86^{\mathrm{a}}$ \\
$\mathrm{T}_{11}(\mathrm{~K})$ & $348-363$ \\
$\mathrm{X}_{20}(\%)$ & 0.95 \\
$\mathrm{PR}$ & $2.55-3.65$ \\
$\Delta \mathrm{T}_{\text {pinch }}(\mathrm{K})$ & $3-15$ \\
$\Delta \mathrm{T}_{\text {pinch_sup }}(\mathrm{K})$ & $0-15$ \\
$\eta_{t 2}(\%)$ & 0.87 \\
$\eta_{p}(\%)$ & 0.87 \\
Fuel cost $(\$ / \mathrm{MWh})$ & $7.4^{\mathrm{a}}$ \\
$\dot{\mathrm{Q}}_{\mathrm{R}}(\mathrm{MW})$ & $600^{\mathrm{a}}$ \\
\hline a Source $[2]$. & \\
&
\end{tabular}


Appropriate values for selected decision variables, thermodynamic properties, and mass, exergy and cost flow rates for the SCRB/KC are shown in Table 6 for a typical operating condition (a workable design). The figures in this table can be helpful in comparing the optimum and base case operating parameters.

Table 6. Thermodynamic properties and exergy stream costs for the SCRB/KC *.

\begin{tabular}{|c|c|c|c|c|c|c|c|c|}
\hline \multirow{2}{*}{ Stream } & \multirow{2}{*}{$\begin{array}{c}\text { Temperature } \\
\text { (K) }\end{array}$} & \multirow{2}{*}{$\begin{array}{l}\text { Pressure } \\
\text { (Bar) }\end{array}$} & \multirow{2}{*}{$\dot{m}(\mathrm{~kg} / \mathrm{s})$} & \multirow{2}{*}{$X(\%)$} & \multirow{2}{*}{$\begin{array}{c}e_{c h} \\
(\mathrm{~kJ} / \mathrm{kg})\end{array}$} & \multirow{2}{*}{$\begin{array}{c}e_{p h} \\
(\mathrm{~kJ} / \mathrm{kg})\end{array}$} & \multicolumn{2}{|c|}{ Costs } \\
\hline & & & & & & & $\dot{C}\left(\frac{\$}{h}\right)$ & $c\left(\frac{\$}{\mathrm{GJ}}\right)$ \\
\hline 1 & 660.19 & 214.6 & 2980 & - & - & 411.4 & 36,646 & 8.304 \\
\hline 2 & 823.15 & 214.6 & 2980 & - & - & 531.5 & 43,456 & 7.622 \\
\hline 3 & 697.15 & 74 & 2980 & - & - & 386.9 & 31,632 & 7.622 \\
\hline 4 & 550.37 & 74 & 2980 & - & - & 299.7 & 24,503 & 7.622 \\
\hline 5 & 408.91 & 74 & 2980 & - & - & 239.9 & 19,614 & 7.622 \\
\hline $5 a$ & 408.91 & 74 & 2187 & - & - & 239.9 & 14,395 & 7.622 \\
\hline $5 b$ & 408.91 & 74 & 793 & - & - & 239.9 & 5219 & 7.622 \\
\hline 6 & 398.3 & 74 & 2187 & - & - & 236.6 & 14,197 & 7.622 \\
\hline 7 & 338.91 & 74 & 2187 & - & - & 221.8 & 13,307 & 7.622 \\
\hline 8 & 308.15 & 74 & 2187 & - & - & 216.6 & 12,998 & 7.622 \\
\hline 9 & 385.88 & 214.6 & 2187 & - & - & 255.8 & 16,604 & 8.245 \\
\hline 10 & 526.48 & 214.6 & 2980 & - & - & 328.4 & 29,480 & 8.368 \\
\hline $10 \mathrm{a}$ & 526.48 & 214.6 & 2187 & - & - & 328.4 & 21,534 & 8.328 \\
\hline $10 \mathrm{~b}$ & 526.48 & 214.6 & 793 & - & - & 328.4 & 7947 & 8.477 \\
\hline 11 & 353 & 32.47 & 191.4 & 0.95 & 18,800 & 392.6 & 130,285 & 9.85 \\
\hline 12 & 353 & 32.47 & 146.3 & 0.9976 & 19,724 & 447.1 & 104,741 & 9.859 \\
\hline 13 & 353 & 32.47 & 45.13 & 0.7957 & 15,731 & 216 & 25,544 & 9.859 \\
\hline 14 & 407.91 & 32.47 & 146.3 & 0.9976 & 19,724 & 493.2 & 104,948 & 9.856 \\
\hline 15 & 323.81 & 10.47 & 146.3 & 0.9976 & 19,724 & 317.5 & 104,036 & 9.856 \\
\hline 16 & 309.14 & 32.47 & 45.13 & 0.7957 & 15,731 & 194.7 & 25,509 & 9.859 \\
\hline 17 & 307.15 & 10.47 & 45.13 & 0.7957 & 15,732 & 191.6 & 25,509 & 9.86 \\
\hline 18 & 309.14 & 10.47 & 191.4 & 0.95 & 18,801 & 286.6 & 129,545 & 9.848 \\
\hline 19 & 308.6 & 10.47 & 191.4 & 0.95 & 18,800 & 286.1 & 129,541 & 9.848 \\
\hline 20 & 301.15 & 10.47 & 191.4 & 0.95 & 18,782 & 267.7 & 129,289 & 9.848 \\
\hline 21 & 301.83 & 32.47 & 191.4 & 0.95 & 18,782 & 271.2 & 129,338 & 9.85 \\
\hline 22 & 304.14 & 32.47 & 191.4 & 0.95 & 18,782 & 271.4 & 129,343 & 9.85 \\
\hline 23 & 314.6 & 32.47 & 191.4 & 0.95 & 18,782 & 273.2 & 129,380 & 9.852 \\
\hline 24 & 298.15 & 1.013 & 43,018 & - & - & 0 & 0 & 0 \\
\hline 25 & 299.15 & 1.013 & 43,018 & - & - & 0.006999 & 266.9 & 246.2 \\
\hline
\end{tabular}

\subsection{Parametric Study}

Parametric studies are performed to reveal the effects on thermodynamic and thermoeconomic performances of the SCRB/KC of modifying various decision variables: compressor pressure ratio $\left(P R_{C}\right)$, pump pressure ratio $\left(\mathrm{PR}_{\mathrm{p}}\right)$, minimum temperature difference in the superheater $\left(\Delta \mathrm{T}_{\text {sup }}\right)$, ammonia concentration in the ammonia-water mixture leaving the condenser $\left(\mathrm{X}_{20}\right)$, pinch point temperature difference in pre-cooler $1\left(\Delta \mathrm{T}_{\mathrm{Pinch}}\right)$, and temperature of ammonia-water solution exiting pre-cooler1 $\left(\mathrm{T}_{11}\right)$. For the $\mathrm{SCRBC}$, the only decision parameter is taken to be the compressor pressure ratio $\left(\mathrm{PR}_{\mathrm{C}}\right)$.

Figure $2 \mathrm{a}, \mathrm{b}$ shows the effects of the compressor pressure ratio $\left(\mathrm{PR}_{\mathrm{C}}\right)$ on the exergy efficiency $\left(\eta_{e x, t o t}\right)$ and total product unit cost $\left(c_{\mathrm{p}, \text { tot }}\right)$ of the SCRBC and the SCRB/KC.

Figure 2a indicates that optimum values exist for $\mathrm{PR}_{C}$ at which the exergy efficiency of the SCRBC or SCRB/KC is maximized. This is justified if we consider that, as the $\mathrm{PR}_{\mathrm{C}}$ increases, the net specific work output for the SCRBC increases and the $\mathrm{CO}_{2}$ mass flow rate decreases, due to the increase in the specific enthalpy difference across the reactor [2]. The increase in net specific work and the decrease in $\mathrm{CO}_{2}$ mass flow rate lead to the maximization of the net produced power for the SCRBC as PR 
increases. As the exergy input to the cycle is constant the variation of exergy efficiency with $\mathrm{PR}_{\mathrm{C}}$ is justified for the SCRBC. A similar discussion can be made for the SCRB/KC noting that the net specific work of the Kalina cycle increases steadily with increasing $\mathrm{PR}_{\mathrm{C}}$. It is clear in Figure $2 \mathrm{a}$ that at higher $P R_{C}$ values the exergy efficiency of the SCRB/KC is flatter than that of the SCRBC. This can be explained if we consider that as the $P R_{C}$ increases the temperature at the inlets of the superheater and pre-cooler1 increase resulting in an increase in the KC exergy input and consequently a higher $\mathrm{KC}$ output power. In addition, the increase in the $\mathrm{KC}$ power output, because of an increase in $\mathrm{PR}_{\mathrm{C}}$, leads to a higher optimum $\mathrm{PR}_{C}$ for the SCRB/KC compared to the corresponding value for the SCRBC, as shown in Figure 2a.

It is observed in Figure $2 b$ that the total product unit cost is minimized at specific values of $P R_{C}$ for both the SCRBC and the SCRB/KC. This is expected based on Equation (15). However, for both cycles, the optimum $\mathrm{PR}_{\mathrm{C}}$ value at which $c_{\mathrm{p} \text {,tot }}$ is minimized is less than the corresponding value at which the exergy efficiency is maximized. This can be explained considering the decrease of associated costs with decreasing $P R_{C}$. It is seen in Figure 2 that the differences in optimum values of $P R_{C}$ for the $\mathrm{SCRBC}$ and the SCRB/KC, for maximum exergy efficiency, are higher than the corresponding values for minimum $c_{p, t o t}$.

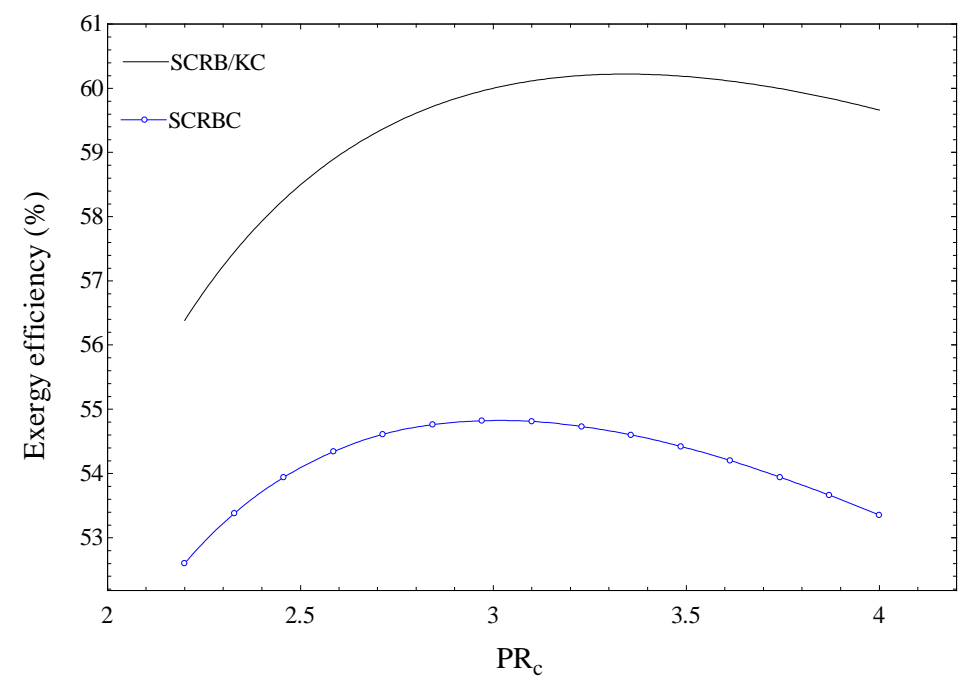

(a)

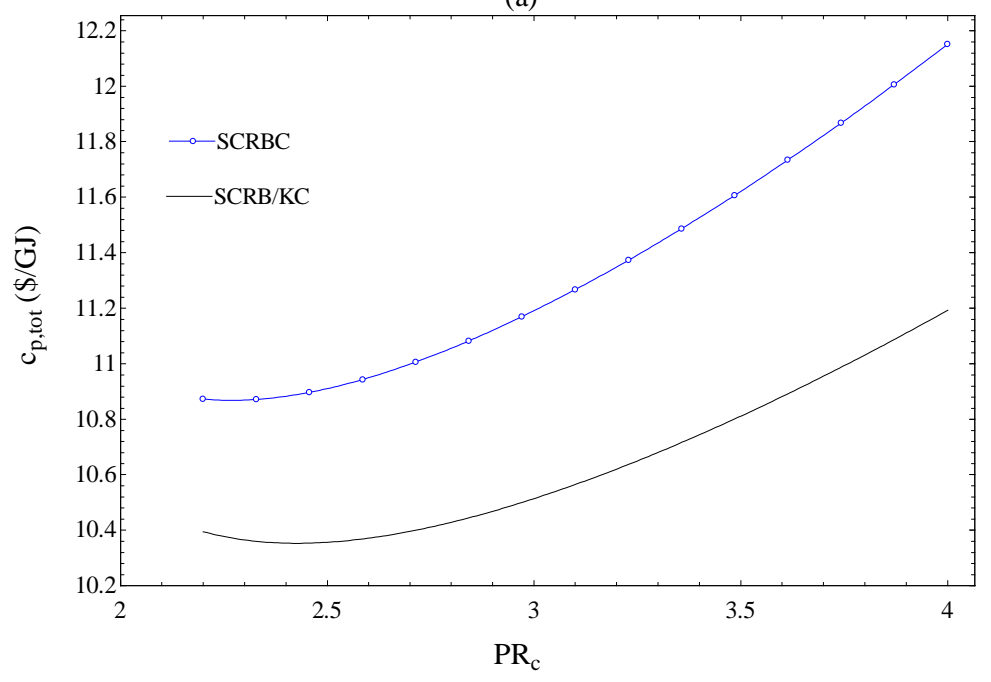

(b)

Figure 2. Effect of compressor pressure ratio $\left(\mathrm{PR}_{\mathrm{C}}\right)$ on: (a) exergy efficiency; and (b) total product unit cost for the SCRBC and the SCRB/KC with base case values. 
The variation of the exergy efficiency $\left(\eta_{\text {ex,tot }}\right)$ and total product unit cost $\left(c_{\mathrm{p}, \text { tot }}\right)$ with the pump pressure ratio $\left(\mathrm{PR}_{\mathrm{P}}\right)$ is shown in Figure 3, for the SCRB/KC. Although the range of variation for the two parameters is small, the trend is interesting. The value of $P R_{P}$ at which the exergy efficiency is maximized is seen in Figure 3 to be the same as that at which the total product unit cost is minimized. This point indicates that, at a given value of $\mathrm{PR}_{\mathrm{P}}$, the changes in $c_{\mathrm{p}, \text { tot }}$ are related only to the net produced power for the $\mathrm{KC}$.

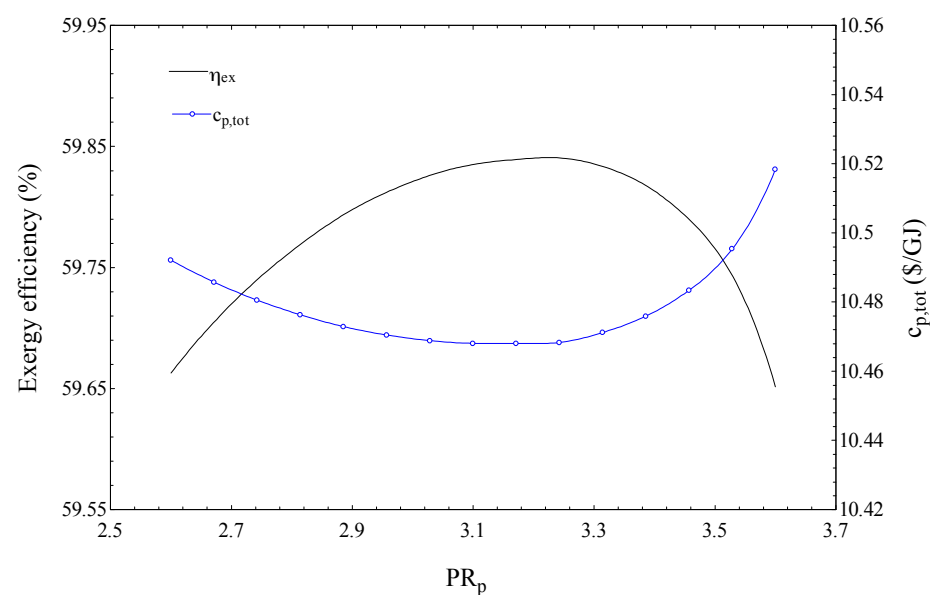

Figure 3. Effect of pump pressure ratio $\left(\mathrm{PR}_{\mathrm{P}}\right)$ on exergy efficiency and total product unit cost for the $\mathrm{SCRB} / \mathrm{KC}$ with base case values.

The maximization of the SCRB/KC exergy efficiency, as $\mathrm{PR}_{\mathrm{b}}$ changes, is actually related to the $K C$ performance. This can be explained by noting that an increase in the $P R_{P}$ causes a decrease in the pre-cooler1 outlet vapor mass fraction $\left(\mathrm{q}_{11}\right)$. This decrease reduces the turbine2 inlet mass flow rate. On the other hand, the increase in $\mathrm{PR}_{\mathrm{P}}$ brings about a higher specific work for the $\mathrm{KC}$ so that the product of the specific work and the mass flow rate is maximized at a specific value of $P R_{P}$. This maximization leads to the maximization for exergy efficiency and the minimization for the total product unit cost for the SCRB/KC.

Figure 4 shows the effects on the exergy efficiency $\left(\eta_{e x, t o t}\right)$ and total product unit cost $\left(c_{\mathrm{p}, \text { tot }}\right)$ of the temperature of the ammonia-water solution at the pre-cooler1 outlet $\left(\mathrm{T}_{11}\right)$ for the SCRB/KC. Although Figure 4 shows that the exergy efficiency is maximized and the total product unit cost is minimized with changing $\mathrm{T}_{11}$, the variations in the objectives are small.

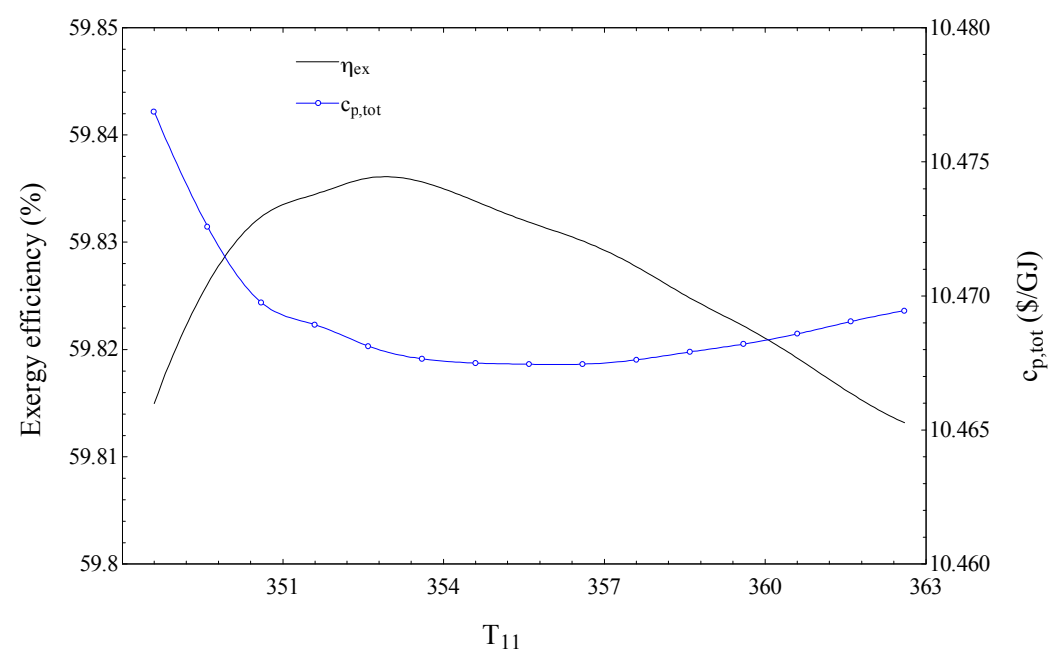

Figure 4. Effect of outlet stream temperature (ammonia-water) of pre-cooler1 $\left(\mathrm{T}_{11}\right)$ on exergy efficiency and total product unit cost for the SCRB/KC with base case values. 
Note that a higher value of $\mathrm{T}_{11}$ results in a lower ammonia-water mass flow rate in the $\mathrm{KC}$, but a higher vapor mass fraction $\left(\mathrm{q}_{11}=\dot{m}_{\text {vapor }} / \dot{m}_{\text {total }}\right)$ in the pre-cooler1 outlet, so that the turbine 2 mass flow rate remains almost constant, i.e., the produced power in the $\mathrm{KC}$ is almost constant. Figure 5 shows the variations in the exergy efficiency and total product unit cost of the SCRB/KC as $\Delta \mathrm{T}_{\text {sup }}$ changes.

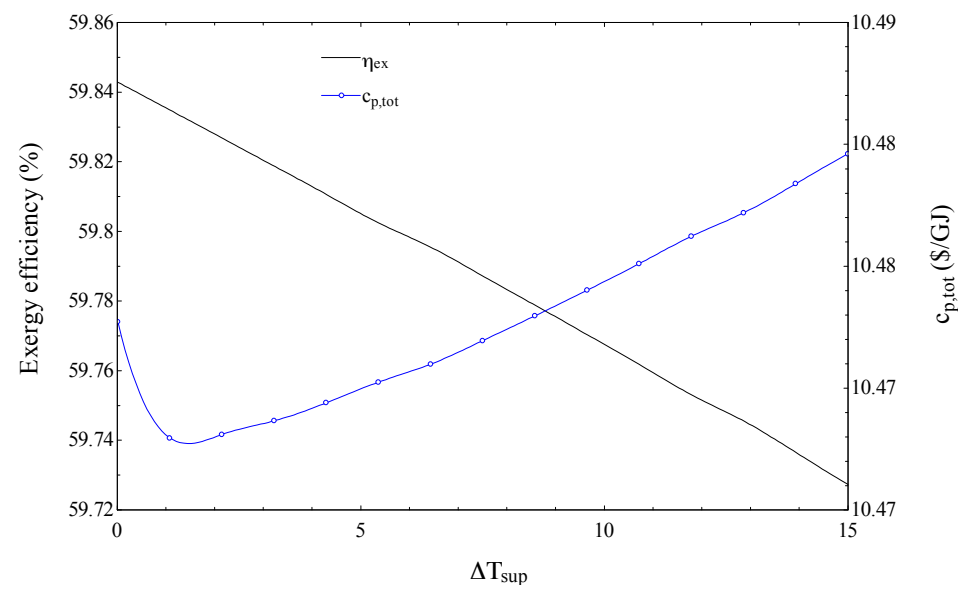

Figure 5. Effect of minimum temperature difference in superheater $\left(\Delta \mathrm{T}_{\text {sup }}\right)$ on the exergy efficiency and total product unit cost for the SCRB/KC for the base case condition.

It can be observed in Figure 5 that, as $\Delta \mathrm{T}_{\text {sup }}$ increases, the exergy efficiency increases and the total product unit cost is minimized. In fact an increase in the $\Delta \mathrm{T}_{\text {sup }}$ causes a decrease in the output power of the KC (because of lower heat recovery in the supeheater) and, consequently, the exergy efficiency of the SCRB $/ K C$ is reduced. However, the increase in $\Delta \mathrm{T}_{\text {sup }}$, brings about a reduction in the superheater capital investment cost rate $\left(\dot{Z}_{S H}\right)$ due to the reduction in the required heat transfer area. Accordingly, as indicated in Figure 5, there exists an optimum value for $\Delta \mathrm{T}_{\text {sup }}$ at which the total product unit cost is minimized.

The effects on the exergy efficiency and total product unit cost of the SCRB/KC are shown in Figure 6 of $\Delta \mathrm{T}_{\text {Pinch }}$ in pre-cooler1. Higher exergy efficiency values are obtained for lower $\Delta \mathrm{T}_{\text {pinch }}$ due to higher values of power generated by the KC. The justification for results in Figure 6 is similar to that for those in Figure 5. However the increase in the cost rate associated with the exergy destruction in pre-cooler1 is dominant so that no minimum value is observed for $c_{p}$,tot.

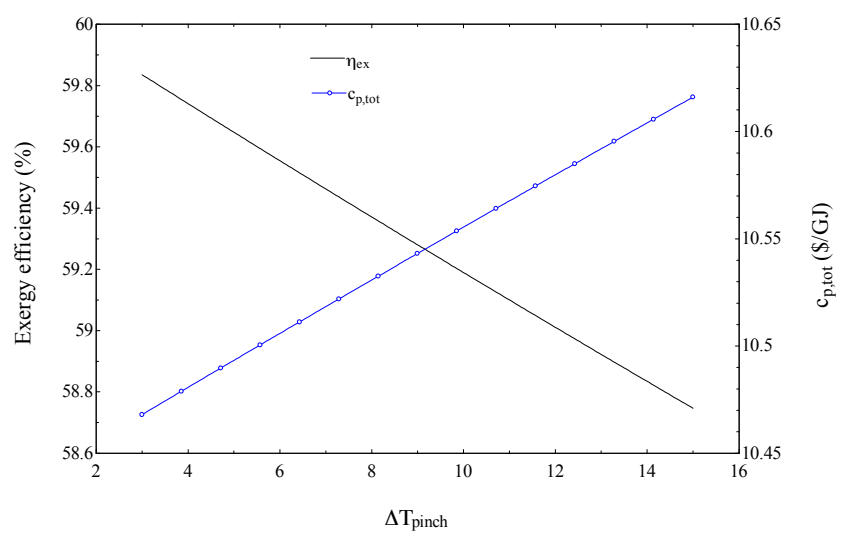

Figure 6. Effect of pinch point temperature difference in pre-cooler1 $\left(\Delta \mathrm{T}_{\text {Pinch }}\right)$ on exergy efficiency and total product unit cost for the SCRB/KC with base case values. 
Figure 7 shows the effects of ammonia concentration in the mixture exiting the condenser $\left(X_{20}\right)$ on the exergy efficiency and total product unit cost of the SCRB/KC. Figure 7 indicates that as $X_{20}$ increases the exergy efficiency increases and the total product unit cost decreases. This is justified if we consider that as $\mathrm{X}_{20}$ increases the exergy destruction in pre-cooler1 and the superheater decreases because of the reduced value of the temperature difference in these two components. Although the reduced value of temperature difference is expected to increase the capital investment cost rate associated with the above-mentioned two components, the increase in produced power is dominant.

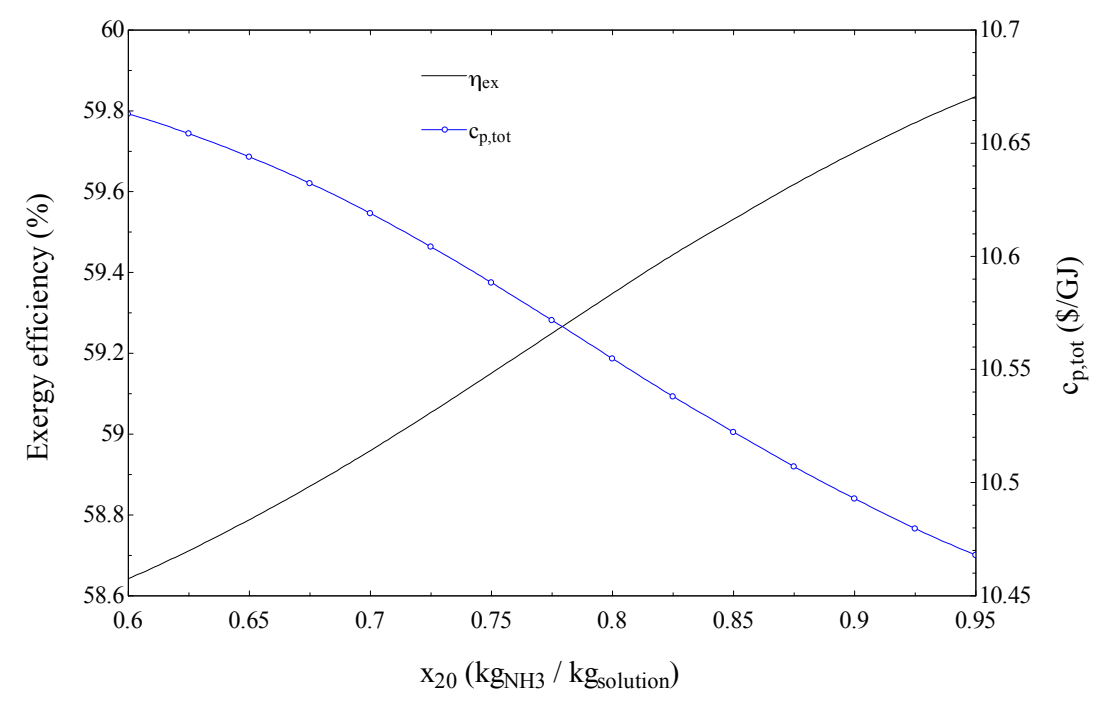

Figure 7. Effect of ammonia concentration in the ammonia-water mixture leaving the condenser $\left(X_{20}\right)$ on exergy efficiency and total product unit cost for the SCRB/KC with base case values.

Table 7 outlines the thermoeconomic parameters for components of the SCRBC and the SCRB/KC. The sum of $\dot{C}_{D}+\dot{Z}$ is observed in Table 7 to be highest and second highest for the reactor core and turbine1 in both the proposed systems, respectively. Therefore, the first design changes initially should be applied to these components. Table 7 also indicates that the exergoeconomic factor is high for these components. This indicates that selecting cheaper components should be suggested for enhancing the economic performance for the systems. However, the extent of improvement in the reactor core is limited. Referring to Table 7, the third highest $\dot{C}_{D}+\dot{Z}$ value is exhibited by pre-cooler2 in the SCRBC. The very low value of $f$ for this component suggests that an increase in its capital cost is merited. It is interesting to note that the second highest exergy destruction rate occurs in pre-cooler2 of the SCRBC and the coupling of the $\mathrm{KC}$ reduces this exergy destruction. In the $\mathrm{KC}$ part of the combined cycle, the highest and second highest values of $\dot{C}_{D}+\dot{Z}$ are associated with turbine 2 and the condenser, respectively. Referring to Table 7 , the small value of $f$ for the condenser suggests it may be appropriate to select a more expensive condenser. 
Table 7. Exergoeconomic variables for components of the SCRBC and SCRB/KC.

\begin{tabular}{|c|c|c|c|c|c|c|c|c|c|c|c|c|}
\hline \multirow{2}{*}{ Component } & \multicolumn{6}{|c|}{ SCRBC } & \multicolumn{6}{|c|}{$\mathrm{SCRB} / \mathrm{KC}$} \\
\hline & $\dot{E}_{D}(\mathrm{MW})$ & $\dot{C}_{D}(\$ / \mathrm{h})$ & $\dot{Z}_{k}(\$ / h)$ & $\dot{C}_{D}+\dot{Z}_{k}+\dot{C}_{L}(\$ / \mathbf{h})$ & $f_{\mathrm{k}}(\%)$ & $r_{k}(\%)$ & $\dot{E}_{D}(\mathrm{MW})$ & $\dot{C}_{D}(\$ / \mathrm{h})$ & $\dot{Z}_{k}(\$ / h)$ & $\dot{C}_{D}+\dot{Z}_{k}+\dot{C}_{L}(\$ / h)$ & $f_{k}(\%)$ & $r_{k}(\%)$ \\
\hline Reactor & 75.43 & 1746 & 5053 & 6799 & 74.32 & 18.55 & 75.43 & 1746 & 5053 & 6799 & 74.32 & 18.55 \\
\hline Turbine1 & 19.73 & 541.3 & 2202 & 2743 & 80.27 & 24.31 & 19.73 & 541.3 & 2202 & 2743 & 80.27 & 24.31 \\
\hline Compressor1 & 11.28 & 384.9 & 297.9 & 682.8 & 43.63 & 23.36 & 11.28 & 384.9 & 297.9 & 682.8 & 43.63 & 23.36 \\
\hline Compressor2 & 6.593 & 224.9 & 108 & 332.9 & 32.45 & 13.9 & 6.593 & 224.9 & 108 & 332.9 & 32.45 & 13.9 \\
\hline Pre_cooler2 & 47.91 & 1315 & 8.541 & 1323.6 & 0.6454 & 32.14 & 10.99 & 301.5 & 7.786 & 309.3 & 2.517 & 4190 \\
\hline HTR & 12.61 & 346.1 & 37.2 & 383.3 & 9.706 & 5.651 & 12.61 & 346.1 & 37.2 & 383.3 & 9.706 & 5.651 \\
\hline LTR & 19.29 & 529.2 & 41.84 & 571.1 & 7.326 & 13.1 & 19.29 & 529.2 & 41.84 & 571.1 & 7.326 & 13.1 \\
\hline Pre_cooler1 & - & - & - & - & - & - & 6.097 & 167.3 & 14.66 & 182 & 8.058 & 25.17 \\
\hline KCHTR & - & - & - & - & - & - & 0.6144 & 21.81 & 1.905 & 23.71 & 8.034 & 189.7 \\
\hline KCLTR & - & - & - & - & - & - & 0.08839 & 3.134 & 1.481 & 4.615 & 32.09 & 384.2 \\
\hline Superheater & - & - & - & - & - & - & 0.4668 & 12.81 & 9.285 & 22.1 & 42.02 & 11.92 \\
\hline Turbine2 & - & - & - & - & - & - & 3.113 & 110.4 & 213.6 & 324.1 & 65.92 & 40.43 \\
\hline Mixer & - & - & - & - & - & - & 0.24 & - & - & - & - & - \\
\hline Valve & - & - & - & - & - & - & 0.051 & - & - & - & - & - \\
\hline Separator & - & - & - & - & - & - & 3.321 & - & - & - & - & - \\
\hline Pump & - & - & - & - & - & - & 0.1012 & 5.043 & 10.01 & 15.05 & 66.49 & 45.57 \\
\hline Condenser & - & - & - & - & - & - & 6.817 & 241.7 & 14.52 & 256.2 & 5.668 & 2400 \\
\hline Overall system & 192.85 & 5087 & 7749 & 12,836 & 86.21 & 47.37 & 176.8 & 4636 & 8013 & 12,650 & 87.58 & 53.08 \\
\hline
\end{tabular}




\subsection{Optimization}

As mentioned in the parametric study section, the only decision parameter for the SCRBC is the compressor pressure ratio $\left(\mathrm{PR}_{\mathrm{C}}\right)$. Thus, the Quadratic Approximations method in the EES software is used to optimize the performance of the SCRBC. For the SCRB/KC, however, five decision parameters are identified, i.e., pump pressure ratio $\left(\mathrm{PR}_{\mathrm{p}}\right)$, output stream temperature (ammonia-water) of pre-cooler1 $\left(\mathrm{T}_{11}\right)$, pinch point temperature difference in pre-cooler1 $\left(\Delta \mathrm{T}_{\text {Pinch }}\right)$, minimum temperature difference in the superheater $\left(\Delta \mathrm{T}_{\text {sup }}\right)$, and ammonia concentration in the ammonia-water mixture leaving the condenser $\left(\mathrm{X}_{20}\right)$. Therefore, the direct search method in the EES software is used to optimize the SCRB/KC performance. The optimization for both the SCRBC and SCRB/KC are performed from the viewpoints of either thermodynamics or thermoeconomics as follows:

For the SCRBC,

Maximize $\eta_{\text {ex, tot }}$ or Minimize $\mathrm{c}_{\mathrm{p}, \text { tot }}\left(\mathrm{PR}_{\mathrm{C}}\right)$

$$
2.2 \leq \mathrm{PR}_{\mathrm{C}} \leq 4
$$

For the SCRB/KC,

Maximize $\eta_{\text {ex,tot }}$ or Minimize $c_{\mathrm{p}, \text { tot }}\left(\mathrm{PR}_{\mathrm{C}} ; \mathrm{PR}_{\mathrm{p}} ; \mathrm{T}_{11} ; \Delta \mathrm{T}_{\text {Pinch }} ; \Delta \mathrm{T}_{\text {sup }}\right)$

$$
\begin{gathered}
2.2 \leq \mathrm{PR}_{\mathrm{C}} \leq 4 \\
2.55 \leq \mathrm{PR}_{\mathrm{p}} \leq 3.65 \\
348 \leq \mathrm{T}_{11}(\mathrm{~K}) \leq 363 \\
3 \leq \Delta \mathrm{T}_{\text {Pinch }} \leq 15 \\
0 \leq \Delta \mathrm{T}_{\text {sup }} \leq 15
\end{gathered}
$$

Optimization Results

The values of decision and performance parameters for the thermodynamic and economic optimal design (TOD and EOD) cases are shown in Table 8 for the SCRBC and the SCRB/KC.

Table 8. Optimum values of decision and performance parameters for the SCRBC and the SCRB/KC.

\begin{tabular}{ccccc}
\hline & \multicolumn{2}{c}{ SCRBC } & \multicolumn{2}{c}{ SCRB/KC } \\
\cline { 2 - 5 } Parameter & \multicolumn{2}{c}{ Optimal Cases } & \multicolumn{2}{c}{ Optimal Cases } \\
\cline { 2 - 5 } & TOD & EOD & TOD & EOD \\
\hline $\mathrm{PR}_{\mathrm{c}}$ & 3.01 & 2.27 & 3.39 & 2.39 \\
$\mathrm{PR}_{\mathrm{p}}$ & - & - & 3.45 & 2.718 \\
$\mathrm{~T}_{11}(\mathrm{~K})$ & - & - & 357.66 & 349.5 \\
$\Delta \mathrm{T}_{\text {sup }}(\mathrm{K})$ & - & - & 0 & 1.5 \\
$\Delta \mathrm{T}_{\text {pinch }}(\mathrm{K})$ & - & - & 3 & 3 \\
$\eta_{\text {ex }}(\%)$ & 54.8 & 53.04 & 60.31 & 57.93 \\
$\mathrm{c}_{\mathrm{p}, \text { tot }}(\$ / \mathrm{GJ})$ & 11.2 & 10.87 & 10.73 & 10.34 \\
$\dot{\mathrm{W}}_{\text {net }}(\mathrm{MW})$ & 237.6 & 229.8 & 261.3 & 251 \\
$\dot{\mathrm{W}}_{\text {net }, \mathrm{SCRBC}}(\mathrm{MW})$ & 237.6 & 229.8 & 236.4 & 232.5 \\
$\dot{\mathrm{W}}_{\text {net, } \mathrm{KC}}(\mathrm{MW})$ & - & - & 24.9 & 18.5 \\
$\dot{m}_{\mathrm{CO}}(\mathrm{kg} / \mathrm{s})$ & 2940 & 3307 & 2.824 & 3227 \\
$\dot{m}_{\mathrm{NH}_{3} / \mathrm{H}_{2} \mathrm{O}(\mathrm{kg} / \mathrm{s})}$ & - & - & 196 & 181 \\
$\dot{\mathrm{Z}}_{\text {tot }}(\$ / \mathrm{h})$ & 7819 & 7291 & 8344 & 7627 \\
$\dot{\mathrm{C}}_{D_{\text {D,tot }}(\$ / \mathrm{h})}$ & 4569.5 & 4949.4 & 4331.5 & 4516.5 \\
$x$ & 0.273 & 0.198 & 0.294 & 0.216 \\
\hline
\end{tabular}

Table 8 indicates that the product unit cost is minimized at a compressor pressure ratio $\left(\mathrm{PR}_{\mathrm{C}}\right)$ lower than the value at which the exergy efficiency is maximized. In fact, the lower value of $P R_{C}$ brings about a lower value of $\dot{Z}$ and the lower value of $\dot{Z}$ results in a lower value of $f$. Therefore, the suggestion of reducing $f$ for turbine1, as made in the discussion about the results in Table 7 , is confirmed here. 
In addition, Table 8 indicates that the $\mathrm{CO}_{2}$ mass flow rate is higher for the EOD case as expected because of the lower value of $\mathrm{PR}_{\mathrm{C}}$ for the EOD case [2]. Referring to Table 8 and comparing the EOD and TOD cases for the SCRBC, a reduction of about $3 \%$ in the total product unit cost is obtained at the expense of about a 3.3\% reduction in the exergy efficiency. Table 8 also indicates that the total capital cost rate $\left(\dot{Z}_{t o t}\right)$ for the SCRBC, when it is optimized for minimum total product unit cost, is reduced by $6.7 \%$ compared to the case when it is optimized for maximum exergy efficiency.

Comparing optimum decision parameter values for the SCRBC and the SCRB/KC in Table 8 shows an enhancement of both the exergy efficiency and $c_{p}$,tot values as the $\mathrm{KC}$ is coupled with the SCRBC. The comparison shows that the exergy efficiency is improved by $10 \%$ and $9.2 \%$ for the TOD and the EOD cases, respectively. Similarly, a reduction of $4.2 \%$ and $4.9 \%$ in $c_{p}$,tot is observed for the TOD and the EOD cases, respectively. In fact, when the KC is combined with the SCRBC, $\dot{Z}_{\text {tot }}$ is increased by $6.7 \%$ and $4.6 \%$ for the TOD and EOD cases, respectively. However, the increases of $10 \%$ and $9.2 \%$ in the net output power (see Table 8 ) for the TOD and EOD cases, respectively, results in a reduction of $c_{p, t o t}$.

A comparison between the results obtained for the EOD cases in Table 8 shows that the exergy destruction cost rate for the overall system is reduced by $8.75 \%$ as the $\mathrm{KC}$ is combined with the SCRBC.

\section{Conclusions}

Thermodynamic and thermoeconomic analyses are carried out for the SCRBC and the SCRB/KC. The performances of the cycles are optimized from the viewpoints of thermodynamics and thermoeconomics. Parametric studies are performed for the cycles to assess the effects on the exergy efficiency and total product unit cost of such decision parameters as compressor pressure ratio, ammonia-water temperature at pre-cooler1 outlet, pinch point temperature difference in pre-cooler1, pump pressure ratio, ammonia concentration at the condenser outlet and minimum temperature difference in the superheater. The results indicate that the SCRB/KC is superior to the SCRBC from the two viewpoints. It is observed that the optimum compressor and pump pressure ratios for minimum total product unit cost are lower than the corresponding values for maximum exergy efficiency. It is found that combining the KC with SCRBC reduces the exergy destruction in the pre-cooler (pre-cooler $1+$ pre-cooler2) by $64.4 \%$ for the TOD case and $61.2 \%$ for the EOD case.

It is concluded that the exergy efficiency of SCRB/KC is higher than that of the SCRBC by up to $10 \%$ and that the total product unit cost for the SCRB/KC is lower than that for the SCRBC by up to $4.9 \%$.

Author Contributions: The modeling was made by Akbari; and analysis as well as discussion were performed by all the authors. All the authors contributed equally in writing the article.

Conflicts of Interest: The authors declare no conflict of interest.

\section{Nomenclature}

$\begin{array}{ll}\mathrm{A} & \text { heat transfer area }\left(\mathrm{m}^{2}\right) \\ \dot{C} & \text { cost rate }(\$ / \mathrm{h}) \\ c & \text { cost per exergy unit }(\$ / \mathrm{GJ}) \\ \mathrm{c}_{\mathrm{p}, \text { tot }} & \text { total product unit cost }(\$ / \mathrm{GJ}) \\ \dot{E} & \text { exergy rate }(\mathrm{kW}) \\ e & \text { specific exergy }(\mathrm{kJ} / \mathrm{kg}) \\ h & \text { specific enthalpy }(\mathrm{kJ} / \mathrm{kg}) \\ i_{r} & \text { interest rate } \\ \dot{m} & \text { mass flow rate }(\mathrm{kg} / \mathrm{s}) \\ \mathrm{P} & \text { pressure }(\text { bar }) \\ \mathrm{PR} & \text { pressure ratio } \\ \mathrm{PR} & \text { compressor pressure ratio } \\ \mathrm{PR} & \text { pump pressure ratio } \\ \dot{\mathrm{Q}} & \text { heat transfer rate }(\mathrm{kW}) \\ s & \text { specific entropy }(\mathrm{kJ} / \mathrm{kg} \mathrm{K})\end{array}$


$\mathrm{T} \quad$ temperature $\left({ }^{\circ} \mathrm{C}, \mathrm{K}\right)$

$\mathrm{T}_{11} \quad$ pre-cooler1 outlet temperature $\left({ }^{\circ} \mathrm{C}, \mathrm{K}\right)$

$\dot{W}_{C} \quad$ compressor power $(\mathrm{kW})$

$\dot{W}_{P} \quad$ pump power $(\mathrm{kW})$

$\dot{W}_{T} \quad$ turbine power $(\mathrm{kW})$

$x \quad$ recompressed mass fraction

$X \quad$ ammonia concentration

Z capital cost of a component (\$)

$\dot{Z} \quad$ capital cost rate $(\$ / \mathrm{h})$

\section{Subscripts and Abbreviations}

$\begin{array}{ll}0 & \text { dead (environmental) state } \\ 1,2,3 \ldots & \text { state points } \\ \text { C } & \text { compressor } \\ \text { ch } & \text { chemical } \\ \text { CI } & \text { capital investment } \\ \text { cond } & \text { condenser } \\ \text { CRF } & \text { capital recovery factor } \\ \text { D } & \text { destruction } \\ \text { EOD } & \text { economic optimal design } \\ \text { F } & \text { fuel } \\ \text { HTR } & \text { high temperature recuperator } \\ \text { LTR } & \text { low temperature recuperator } \\ \text { OM } & \text { operation and maintenance } \\ \text { p } & \text { pump, product } \\ \text { pc } & \text { pre-cooler } \\ \text { ph } & \text { physical } \\ \text { R } & \text { reactor } \\ \text { sup } & \text { superheater } \\ \text { T } & \text { turbine } \\ \text { TOD } & \text { thermodynamic optimal design }\end{array}$

\section{Greek Symbols}

$\begin{array}{ll}\epsilon & \text { effectiveness } \\ \eta_{t h} & \text { thermal efficiency } \\ \eta_{e x} & \text { exergy efficiency } \\ \eta_{i s} & \text { isentropic efficiency } \\ \Delta \mathrm{T} & \text { minimum temperature difference } \\ \Delta \mathrm{T}_{\text {pinch }} & \text { pinch point temperature difference }\end{array}$

\section{Appendix A}

Appropriate cost functions are employed to assess the investment costs of system components in both cycles. Table A1 lists these cost functions for components of the analyzed systems [2,30].

Table A1. Cost functions for economic modeling.

\begin{tabular}{cc}
\hline Component & Capital Investment Cost Function \\
\hline Reactor & $Z_{R}=C_{1} \times \dot{Q}_{r}, C_{1}=283 \$ / K W_{t h}[2]$ \\
Turbine1 & $Z_{T 1}=479.34 \times \dot{m}_{i n}\left[\frac{1}{0.93-\eta_{t 1}}\right] \times \ln \left(P R_{c}\right) \times\left(1+e^{\left(0.036 \times T_{2}-54.4\right)}\right)[2]$ \\
Compressors & $Z_{C 1 \& 2}=71.1 \times \dot{m}_{i n}\left[\frac{1}{0.92-\eta_{c}}\right] \times P R_{c} \times \ln \left(P R_{c}\right)[2]$ \\
HTR, LTR, Pre-cooler1 & $Z_{k}=2681 \times A_{k}^{0.59}[2]$ \\
Condenser, Pre_cooler2 & $Z_{k}=2143 \times A_{k}^{0.514}[2]$ \\
KCHTR, KCLTR & $Z_{k}=2143 \times A_{k}^{0.514}[29]$ \\
Superheater & $Z_{k}=2681 \times A_{k}^{0.59}[29]$ \\
Turbine2 & $Z_{T 2}=4405 \times \dot{W}_{T 2}^{0.7}[29]$ \\
Pump & $Z_{P}=1120 \times \dot{W}_{p}^{0.8}[29]$ \\
\hline
\end{tabular}


As the costs associated with the mixer, the throttling valve and the separator are much less than those for the other components, they are neglected in the analyses [29].

The cost functions for shell and tube heat exchangers are adopted for pre-cooler2 of the SCRBC and all the heat exchangers in the Kalina cycle. For the high and low temperature recuperators as well as pre-cooler1 and the superheater, the cost functions suggested for compact heat exchangers are selected $[2,30]$.

To simulate the thermal behavior of heat exchangers the logarithmic mean temperature difference $\left(\Delta T_{k}^{l m}\right)$ method is used. In this method, the heat transfer rate is described as:

$$
q_{k}=U_{k} A_{k} \Delta T_{k}^{l m}
$$

where $A_{k}$ is the surface area of the heat exchanger and $U_{k}$ is the overall heat transfer coefficient [2].

The cost of system components in the reference year can be calculated using costs available in the original year and the Chemical Engineering Plant Cost Index (CEPEI):

$$
\text { Cost at reference year }=\text { Original Cost } \times \frac{\text { Cost index for the reference year }}{\text { Cost index for the original year }}
$$

\section{References}

1. Yang, M.H.; Yeh, R.H. Analyzing the optimization of an organic Rankine cycle system for recovering waste heat from a large marine engine containing a cooling water system. Energy Convers. Manag. 2014, 88, 999-1010. [CrossRef]

2. Akbari, A.D.; Mahmoudi, S.M.S. Thermoeconomic analysis and optimization of the combined supercritical $\mathrm{CO}_{2}$ (carbon dioxide) recompression Brayton/organic Rankine cycle. Energy 2014, 78, 501-512. [CrossRef]

3. Chen, Y.; Lundqvist, P.; Johansson, A.; Platell, P. A comparative study of the carbon dioxide transcritical power cycle compared with an organic rankine cycle with R123 as working fluid in waste heat recovery. Appl. Therm. Eng. 2006, 26, 2142-2147. [CrossRef]

4. Feher, E.G. The supercritical thermodynamic power cycle. Energy Convers. 1968, 8, 85-90. [CrossRef]

5. Angelino, G. Carbon dioxide condensation cycles for power production. 1968, 90, 287-295. [CrossRef]

6. Dostal, V. A supercritical Carbon Dioxide Cycle for Next Generation Nuclear Reactors. Ph.D. Thesis, Massachusetts Institute of Technology, Cambridge, MA, USA, 2004.

7. Cayer, E.; Galanis, N.; Desilets, M.; Nesreddine, H.; Roy, P. Analysis of a carbon dioxide transcritical power cycle using a low temperature source. Appl. Energy 2009, 86, 1055-1063. [CrossRef]

8. Angelino, G.; Invernizzi, C.M. Carbon dioxide power cycles using liquid natural gas as heat sink. Appl. Therm. Eng. 2009, 29, 2935-2941. [CrossRef]

9. Sarkar, J. Second law analysis of supercritical $\mathrm{CO}_{2}$ recompression Brayton cycle. Energy 2009, 34, 1172-1178. [CrossRef]

10. Sarkar, J.; Bhattacharyya, S. Optimization of recompression $\mathrm{S}-\mathrm{CO}_{2}$ power cycle with reheating. Energy Convers. Manag. 2009, 50, 1939-1945. [CrossRef]

11. Wang, J.; Sun, Z.; Dai, Y. Parametric optimization design for supercritical $\mathrm{CO}_{2}$ power cycle using genetic algorithm and artificial neural network. Appl. Energy 2010, 87, 1317-1324. [CrossRef]

12. Yari, M.; Sirousazar, M. A novel recompression $\mathrm{S}-\mathrm{CO}_{2}$ Brayton cycle with pre-cooler exergy utilization. J. Power Energy 2010, 224, 931-946. [CrossRef]

13. Jeong, W.S.; Lee, J.I.; Jeong, Y.H. Potential improvements of supercritical recompression $\mathrm{CO}_{2}$ Brayton cycle by mixing other gases for power conversion system of a SFR. Nucl. Eng. Des. 2011, 241, 2128-2137. [CrossRef]

14. Yoon, H.J.; Ahn, Y.; Lee, J.I.; Addad, Y. Potential advantages of coupling supercritical $\mathrm{CO}_{2}$ Brayton cycle to water cooled small and medium size reactor. Nucl. Eng. Des. 2012, 245, 223-232. [CrossRef]

15. Kim, Y.M.; Kim, C.G.; Favrat, D. Transcritical or supercritical $\mathrm{CO}_{2}$ cycles using both low- and high-temperature heat sources. Energy 2012, 43, 402-415. [CrossRef] 
16. Floyd, J.; Alpy, N.; Moisseytsev, A.; Haubensack, D.; Rodriguez, G.; Sienicki, J.; Avakian, G. A numerical investigation of the $\mathrm{S}-\mathrm{CO}_{2}$ recompression cycle off-design behaviour, coupled to a sodium cooled fast reactor, for seasonal variation in the heat sink temperature. Nucl. Eng. Des. 2013, 260, 78-92. [CrossRef]

17. Singh, R.; Kearney, M.P.; Manzie, C. Extremum-seeking control of a supercritical carbon-dioxide closed Brayton cycle in a direct-heated solar thermal power plant. Energy 2013, 60, 380-387. [CrossRef]

18. Moullec, Y.L. Conceptual study of a high efficiency coal-fired power plant with $\mathrm{CO}_{2}$ capture using a supercritical $\mathrm{CO}_{2}$ Brayton cycle. Energy 2013, 49, 32-46. [CrossRef]

19. Nithyanandam, K.; Pitchumani, R. Cost and performance analysis of concentrating solar power systems with integrated latent thermal energy storage. Energy 2014, 64, 793-810. [CrossRef]

20. Dai, B.; Li, M.; Ma, Y. Thermodynamic analysis of carbon dioxide blends with low GWP (global warming potential) working fluids-based transcritical Rankine cycles for low-grade heat energy recovery. Energy 2014, 64, 942-952. [CrossRef]

21. Mondal, S.; De, S. Transcritical $\mathrm{CO}_{2}$ power cycle-Effects of regenerative heating using turbine bleed gas at intermediate pressure. Energy 2015, 78, 95-103. [CrossRef]

22. Hu, L.; Chen, D.; Huang, Y.; Li, L.; Cao, Y.; Yuan, D.; Wang, J.; Pan, L. Investigation on the performance of the supercritical Brayton cycle with $\mathrm{CO}_{2}$-based binary mixture as working fluid for an energy transportation system of a nuclear reactor. Energy 2015, 89, 874-886. [CrossRef]

23. Padilla, R.V.; Too, Y.C.S.; Benito, R.; Stein, W. Exergetic analysis of supercritical $\mathrm{CO}_{2}$ Brayton cycles integrated with solar central receivers. Appl. Energy 2015, 148, 348-365. [CrossRef]

24. Gholamian, E.; Mahmoudi, S.M.S.; Zare, V. Proposal, exergy analysis and optimization of a new biomass-based cogeneration system. Appl. Therm. Eng. 2016, 93, 223-235. [CrossRef]

25. Ganesh, N.S.; Srinivas, T. Thermodynamic assessment of heat source arrangements in Kalina power station. J. Energy Eng. 2013, 139, 99-108. [CrossRef]

26. Bejan, A.; Tsatsaronis, G.; Moran, M. Thermal Design and Optimization; John Wiley and Sons: New York, NY, USA, 1996.

27. Dincer, I.; Rosen, M.A. Exergy: Energy, Environment and Sustainable Development, 2nd ed.; Elsevier: New York, NY, USA, 2013.

28. Ogriseck, S. Integration of Kalina cycle in a combined heat and power plant, a case study. Appl. Therm. Eng. 2009, 29, 2843-2848. [CrossRef]

29. Zare, V.; Mahmoudi, S.M.S.; Yari, M. On the exergoeconomic assessment of employing Kalina cycle for GT-MHR waste heat utilization. Energy Convers. Manag. 2015, 90, 364-374. [CrossRef]

30. Lazzaretto, A.; Tsatsaronis, G. SPECO: A systematic and general methodology for calculating efficiencies and costs in thermal systems. Energy 2006, 31, 1257-1289. [CrossRef] 